\title{
O FUNDAMENTO DA JUSTIÇA DISTRIBUTIVA EM SÃO TOMÁS DE AQUINO: UMA CRÍTICA AO LIBERTARIANISMO DE ROBERT NOZICK
}

\section{Eduardo Seino Wiviurka ${ }^{1}$}

\section{RESUMO}

Duas classificações sobre a justiça são apresentadas e comparadas neste estudo - que enfatiza as consequências das diferenças existentes. Para isso, de um lado apresenta a classificação clássica aristotélico-tomista, que será discutido a partir do New Natural Law; e de outro lado a classificação de justiça que surgiu a partir do século XVI com o Cardeal Cajetano e as consequências mais extremas deste modelo expresso no Libertarianismo de Robert Nozick -marco teórico foi eleito ter o maior contraste com o pensamento tomista. A importância de compreender as diferenças entre as classificações de justiça reside no fato de que elas produzem consequências no debate filosófico, em especial em questões morais e fundamentos para a justiça redistributiva feita através de instituições estatais. Trata-se de uma pesquisa bibliográfica, que utiliza um método comparativo, identificando em ambas as vertentes os conceitos essenciais - a classificação da justiça e fundamento do direito da propriedade - e apresenta uma sistematização das diferenças. Como resultado da análise feita, identifica como principal divergência entre os modelos o trato para deveres morais positivos. Tal estudo apresenta elementos teóricos essenciais do New Natural Law e também oferecer um sólido contraponto ao pensamento de Nozick.

Palavras-chave: John Finnis; Lei Natural; Propriedade; Classificação da Justiça; Deveres Morais.

\section{INTRODUÇÃO}

O New Natural Law é uma vertente filosófica do final do século XX que promove um resgate do pensamento de São Tomás de Aquino. Germain Grisez e John Finnis são dois nomes que

\footnotetext{
${ }^{1}$ Doutorando em Filosofia pela Universidade Federal do Paraná, na linha de pesquisa História da Filosofia. Mestre em Direito pela Universidade Federal do Paraná, na linha de pesquisa de Direito do Estado. Especialista em Formação Pedagógica do Professor Universitário pela Pontifícia Universidade Católica do Paraná - PUCPR. Bacharel em Direito pelo Centro Universitário Curitiba. Coordenador do Grupo de Pesquisa Direito e Liberdade. Professor de Filosofia e Direito Constitucional do Centro Universitário Curitiba. Centro Universitário Curitiba, Paraná $\quad-\quad$ Brasil. ORCI http://orcid.org/0000-0003-3813-3522 E-mail: seinoew@gmail.com
} 
inauguraram este debate. Dentre as contribuições deles, está uma contraposição entre a classificação da justiça pensada por filosóficos clássicos e a justiça em uma classificação recente. Na vertente clássica situam-se Aristóteles e São Tomás. Na vertente recente, por vezes referida como atual ou contemporânea, localizam-se autores como John Rawls e Robert Nozick que constituem importantes vozes no debate contemporâneo acerca de teorias da justiça.

A importância de compreender as diferenças entre as classificações de justiça reside no fato de que elas produzem consequências contrapostas no debate filosófico. Vertentes diferentes terão compreensões variadas sobre um mesmo fenômeno, e o contraste mais significante aparece no que concerne à justiça distributiva.

Para guiar esta exposição formula-se o seguinte questionamento: temos deveres morais positivos em relação aos outros? Por deveres morais positivos devemos entender obrigações para com os outros, independentemente de legislação jurídica. Se a resposta do questionamento formulado for positiva, como faz a vertente clássica, então um sujeito tem dever moral de agir justamente, conforme virtude, em relação aos outros - e isso será o fundamento da concepção clássica de justiça distributiva. Se a resposta para o questionamento for negativa, como resulta com o percurso argumentativo realizado por Nozick, não haveria obrigação moral de um sujeito ajudar o outro, apenas de evitar danos - ou seja, deveres morais negativos. O desdobramento desta questão, como acontece na argumentação libertária, é discutir o estatuto moral de taxação por parte do Estado com fins de promover políticas redistributivas.

Para a exposição destas respostas contrapostas o presente artigo estrutura-se em duas partes: inicialmente apresenta a leitura de Finnis sobre a justiça em São Tomás, pontuando conceitos essenciais que servem como base para a compreensão do lugar da justiça na Filosofia do Direito do New Natural Law; posteriormente discute uma nova classificação de justiça que surgiu a partir do século XVI com o Cardeal Cajetano e as consequências mais extremas deste modelo expresso no pensamento de Nozick.

Entre São Tomás e Nozick existem teorias com posições intermediárias que mereceriam consideração. A escolha desses marcos teóricos deve-se ao fato de serem modelos contrapostos mais expressivos. Esses autores realizam leituras significativamente diferentes sobre justiça distributiva. As críticas feitas também podem muito bem servir para objetar premissas de outras teorias da justiça além do libertarianismo nozickiano.

\section{A JUSTIÇA CLÁSSICA NO PENSAMENTO DE SÃO TOMÁS DE AQUINO}

A justiça foi objeto de diversas formulações filosóficas e jurídicas, possuindo incontáveis semânticas possíveis. Entre as diversas formulações, como a justiça como uma das quatro virtudes 
cardeais ou enquanto exigência da razão prática, o ponto de convergência é que podemos chamar de justa a pessoa que respeita o direito dos outros. ${ }^{2}$ A justiça em São Tomás, para ser completamente compreendida, deve ser vista como parte de um todo maior e relacionada com a lei, que por sua vez faz parte de uma teoria moral, que é parte da compreensão do homem. Não obstante haja toda uma arquitetura de um sistema tomista, é possível visitar uma questão específica e desdobrar discussões pertinentes.

\subsection{ELEMENTOS DA JUSTIÇA}

A tradição clássica, partindo de Platão e Aristóteles, identificou três elementos essências da justiça que são aceitos pelos autores contemporâneos - apesar de por vezes serem propostas subdivisões (FINNIS, 2007, p. 161-3; MONTORO, 2008, p. 157-186). São elas:

a) Intersubjetividade, por vezes também referida como alteridade. Só há justiça ou injustiça em uma relação com pluralidade de sujeitos, ou seja, ela sempre é voltada a outrem. Nesta relação pode haver indivíduos, enquanto cidadãos privados, e todos do qual eles fazem parte, tendo como modelo mais acabado a Sociedade Civil e o Estado. Se a pessoa é justa consigo mesma constitui outro problema da teoria moral;

b) Dever ou um débito para com outra parte, algo que pode ser exigido. A relação entre as partes gera uma obrigação de prestação de natureza distributiva ou comutativa, conforme será discutido adiante. Em termos recentes fala-se da existência de um direito subjetivo;

c) Finalmente a Igualdade, também chamada de simetria, ou proporcionalidade como prefere Finnis. Aristóteles entende que a igualdade pode ser aritmética, igualdade simples ou absoluta usada em relações de justiça comutativa, ou geométrica, que visa uma proporcionalidade própria de relações que envolvem justiça distributiva (ARISTÓTELES, 1999, p 97-8).

Em toda relação concreta em que a justiça, ou a sua falta, pode ser mensurada os três elementos descritos serão analisados. Quando falamos que uma pessoa agiu de forma justa, significa que ela em relação a outrem cumpriu seu dever de forma proporcional. Também nos referimos como justa a política pública, feita pelo Estado em relação aos indivíduos, que distribui cargos

\footnotetext{
${ }^{2}$ São Tomás coloca a seguinte definição de justiça: "A justiça é o habitus, pelo qual, com vontade constante e perpétua, se dá a cada um o seu direito" (II-II q. 58, a.1).
} 
sociais de forma equitativa, mas sempre atentando para as circunstâncias concretas de dada realidade.

\title{
2.2 CLASSIFICAÇÃO DA JUSTIÇA
}

$\mathrm{Na}$ vertente clássica a justiça é inicialmente considerada de forma geral e depois em suas duas formas particulares, comutativa e distributiva.

A justiça geral, também legal e por vezes de social ${ }^{3}$, direciona todas as virtudes para o bem comum. Bem comum deve ser entendimento como o conjunto de condições de colaboração que intensifica a oportunidade de florescimento de todos, isso inclui a coordenação de ação e nãointerferência mútua (FINNIS, 2007, p. 155). O correto bem comum não é maximização dos interesses egoístas, mas sim nos obriga a seguir o bem comum que inclui os outros. É nesta orientação pelos bens dos outros que a justiça foi primariamente concebida, conforme ensina o escolástico (II-II, q. 58, a.5 s) ${ }^{4}$ :

\begin{abstract}
A justiça ordena o homem em suas relações com outrem. O que se pode dar de duas maneiras. Com outrem, considerando singularmente; ou com outrem, em geral, considerando que quem serve a uma comunidade, serve a todos os indivíduos que a ela pertencem. Oras, a ambos esses modos se pode aplicar a justiça em sua noção própria. É manifesto, com efeito, que todos os que pertencem a uma comunidade têm com ela a mesma relação das partes para com o todo. Ora, a parte, por tudo o que ela é, pertence ao todo e qualquer bem da parte deve se ordenar ao bem do todo. Assim o bem de cada virtude, quer ordene a outras pessoas, comporta uma referência ao bem comum, ao qual orienta a justiça. Dessa maneira, os atos de todas as virtudes podem pertencer à justiça, enquanto esta orienta o homem ao bem comum. Neste sentido, a justiça é uma virtude geral. E como compete à lei ordenar o homem ao bem comum, como já foi dito, essa justiça geral é chamada legal; pois, na verdade, por ela, o homem se submete à lei que orienta ao bem comum os atos de todas as virtudes (AQUINO,2005, p. 6364).
\end{abstract}

\footnotetext{
${ }^{3}$ A posição majoritária dos teólogos é que justiça social é idêntica à justiça legal que São Tomás se refere. A justiça legal em São Tomás é caracterizada pela orientação ao bem comum. Justiça social como vista hoje, assim como a justiça legal em São Tomás, tem em comum o bem comum. Para a primeira aparece na finalidade, na segunda no objeto formal. Tal noção foi desvirtuada pelo positivismo jurídico que enfatizou a justiça legal como mero dever de obedecer à lei positiva. Porém, em São Tomás a justiça legal já tem como finalidade o bem comum, como finalidade de toda lei, não apenas a positiva. Para evitar o legalismo, devemos ler Aquino como defensor de uma justiça social.

${ }^{4}$ Todas as questões referências são da Suma Teológica.
} 
São Tomás segue Aristóteles na classificação de justiça em geral e particular. Como virtude geral, a justiça direciona todas as outras virtudes em direção ao bem comum. A justiça nos orienta em relação ao outro e às outras comunidades. Na leitura de Finnis, a justiça é um requisito de razoabilidade prática, dentre outros existentes. Toda ação busca realizar um bem humano em si mesma, mas ao fazer isso deve respeitar os bens humanos na comunidade, ou seja, considerar o bem comum. Esse conjunto de requisitos de razoabilidade prática são variados porque a pessoa deve buscar realizar e respeitar os bens humanos básicos para seu próprio bem e para o bem comum (FINNIS, 2007, p 127). A pretensão de Finnis é explicar mais fenômenos em que a justiça aparece do que fez Aristóteles (justiça na relação entre homens participantes da comunidade política), ou Rawls que restringe a discussão da justiça às instituições sociais básicas, muito menos se restringe às condições ideias propostos por ele para a sociedade em que todos agem de acordo com os princípios e instituições de justiça. De certa forma, agir de acordo com a justiça, enquanto exigência da razoabilidade prática, requer que a pessoa respeite outros princípios da razoabilidade prática. Por isso que Aristóteles identifica justiça geral com a virtude de forma abrangente (FINNIS, 2007, p. 163). Finnis, indo além da leitura de Aristóteles, discute justiça considerando o bem comum e os requisitos da razoabilidade prática. Abandona o termo justiça legal e trata como sendo:

Justiça, enquanto qualidade de caráter, é, em seu sentido geral, sempre uma disposição prática a favorecer e fomentar o bem comum de suas comunidades, e a teoria da justiça é, em todas as suas partes, a teoria do que em linhas gerais é requerido para esse bem comum (FINNIS, 2007, p. 165).

Além da justiça geral, que orienta as ações das pessoas em relação ao bem com comum, existe a justiça particular, que orienta as pessoas em relação a outros, cuidando de bens particulares. São Tomás, na questão II-II q. 58, a.7, esclarece que:

Além da justiça legal, que ordena o homem imediatamente ao bem comum. Fazse necessário que haja outras virtudes que o ordenem imediatamente no que toca aos bens particulares. Estes podem dizer respeito a nós mesmos ou a outra pessoa particular. Ora, como, além da justiça legal, são necessárias virtudes particulares que ordenam o homem em si mesmo, por exemplo, a temperança e a fortaleza, assim, igualmente deve haver uma justiça particular que o ordene em suas relações com outras pessoas singulares (AQUINO, 2005, p. 67).

Note-se que a orientação ao bem comum permanece de forma mediata nas formas particulares da justiça. A justiça legal orienta-se imediatamente ao bem comum, e suas espécies 
promovem um bem particular de forma direta, e se isso for feito de forma proporcional, promove de forma mediata o bem comum. Isso acontece em ambas as espécies de justiça particular: comutativa e distributiva (ARISTÓTELES, 1998, p. 93). São Tomás trata desta classificação em IIII, q. 61, a.1.

Já ficou dito, a justiça particular se ordena a uma pessoa privada, que está para a comunidade como a parte para o todo. Ora, uma parte comporta uma dupla relação. Uma, de parte a parte, à qual corresponde a relação de uma pessoa privada a outra. Tal relação é dirigida pela justiça comutativa, que visa o intercâmbio mútuo entre duas pessoas. A outra relação é do todo às partes; a ela se assemelha a relação entre o que é comum e cada uma das pessoas. A essa segunda relação se refere a justiça distributiva, que parte o que é comum de maneira proporcional. Há, portanto, duas espécies de justiça, a comutativa e a distributiva (AQUINO, 2005, p. 97-98)

As formas particulares de justiça também podem ocorrer entre indivíduos, ou entre indivíduos e todos, como a sociedade ou o Estado, que o indivíduo faz parte. Assim, de forma analítica, surgem quatro relações possíveis de justiça (FINNIS, 2007, p. 164-182; MONTORO, 2008, p. 186-288):

a) Justiça comutativa aplicada entre indivíduos, como por exemplo duas pessoas resolvem celebrar um contrato de compra e venda de um objeto, ou quando uma pessoa causa um dano a outra e surge a obrigação de reparar de forma proporcional o dano causado;

b) Justiça comutativa entre o indivíduo e um todo, quando por exemplo o indivíduo comete um crime e deve receber uma pena justa e proporcional para sua conduta;

c) Justiça distributiva entre o todo e um indivíduo, por exemplo na distribuição de cargos e recursos do Estado. Nesta situação, Finnis exemplifica "Um governo que designa um membro do partido sem competência a cargo público viola a justiça distributiva, assim como um magistrado tendencioso" (FINNIS, 2007, p.167);

d) Justiça distributiva entre indivíduos, relação que aparece no correto uso da propriedade. ${ }^{5}$ Tem como alvo a razoabilidade prática exigida de pessoas particulares, dos indivíduos. Não versa diretamente sobre um estado de coisas.

\footnotetext{
${ }^{5}$ Sobre esse ponto, por ser o que mais diverge com a classificação recente, é necessário um aprofundamento maior que será feito na seção seguinte.
} 
Sobre a última forma específica de justiça, é necessário um aprofundamento para os objetivos deste estudo.

\subsection{A PROPRIEDADE EM SÃO TOMÁS DE AQUINO}

A justiça distributiva encaminha-se para o bem comum na medida em que intensifica o conjunto de condições de florescimento humano - a eudaimonia. Essa concepção de bem comum deve ser entendida como o conjunto de condições de colaboração que intensifica a oportunidade de florescimento de todos, isso inclui a coordenação de ação e não-interferencia mútua (FINNIS, 2007, p.167).

Tais ações elvolvem recursos, e nisso as discussões sobre justiça distributiva recaem inevitavelmente em questões de propriedade. A forma como um filósofo pensa a propriedade diz muito sobre sua concepção de justiça. São Tomás será um defensor da propriedade privada, porém colocará critérios formais que irão limitar seu exercício. Nisso, um dos primeiros problemas concernentes ao bem comum refere-se à distribuição de recursos - que será justa se a alocação de algo comum for adequada. Uma coisa pode ser comum de dois modos: não foi criada por ninguém e não é obrigação de qualquer pessoa individual, podemos colocar aqui os recursos naturais; de outro modo surge da disposição de indivíduos em colaborar para melhorar a situação, que por sua vez pode ser dado de dois modos, enquanto distribuição de cargos e funções e produtos do estoque em comum. Em todos os casos é necessário alguma apropriação de algo originalmente comum. Nisso, a questão central da justiça distributiva é definir quem e em quais condições acontecerão as distribuições e redistribuições de forma equitativa (AQUINO, 2005, p. 156-159). ${ }^{6}$

O que chamamos direito de propriedade sempre é invocado em relação a outras pessoas, em razão de uma justiça interpessoal, para reivindicar deveres negativos em relação a determinada propriedade. São Tomás não trata do modo como direitos de propriedade são adquiridos, mas reconhece que tomar posse de algo que antes era comum como legítimo meio de aquisição. Mas tal apropriação precisa trazer benefícios para os membros da comunidade (seja por meio de consumo ou distribuição), do contrário seria injustificada. Por outro lado, há três razões contrárias a permanencia da propriedade com titularidade comum, são elas: 1 quando algo é possuído de forma comum aquilo tende a ser negligenciado, 2 as pessoas poderiam evitar trabalhar para cuidar do que é comum, 3 gerenciamento ineficiente, a situação como um todo tende a provocar desentendimentos. Finnis também tece uma série de considerações que favorece a esfera privada,

\footnotetext{
${ }^{6}$ Apesar de ser uma exigência de justiça formal, (tratar os casos iguais de modo igual), em justiça distributiva é um critério subsidiário. Ou seja, quando que atribui o tratamento desigual. O objetivo da justiça não é igualdade, mas o bem comum, o florescimento de todos os membros da comunidade. Desigualdade não é injusta em si. Mas as utilização de recursos por poucos quando muitos poderiam dar melhor uso atenta contra o bem comum.
} 
assegurando a existência de uma. Defende que iniciativa privada gerencia melhor os recursos que o Poder Público. Por outro lado reconhece que o desapego à propriedade privada produziria mais benefícios para todos. De todo modo, conforme Finnis: "O uso final de recursos consumidos deve permanecer fundamentalmente comum (desapropriado). Qualquer apropriação de recursos para proprietários particulares sempre estará sujeita a esta reserva" (FINNIS, 1998, p. 190). ${ }^{7}$

Uma vez aquirida a propriedade privada, seu detentor passa a ter deveres para que haja produção de mais bens. Caso não cumpra tal função, deve passar adiante a propriedade para que outra pessoa o faça - e assim contribuindo para o bem comum. Por isso que para a visão tomista a existência de latinfundios não produtivos viola a justiça distributiva. Finnis também coloca neste rol especulações financeiras de propriedades sem qualquer uso econômico ou desenvolvimento. Assim como monopólios, oligopólios, acumulação de recursos.

O propósito, de acordo com a justiça, da propriedade privada é dar ao possuidor o uso primário e a fruição de seus frutos, pois é essa disponibilidade que intensifica sua autonomia razoável e estimula sua produtividade e proteção (FINNIS, 2007, p.171).

Mas nessa linha de raciocínio, o que justifica o proprietário útil e necessário? São Tomás, na II-II q. 57 a3c, esclarece que nenhum recurso pertence naturalmente a uma pessoa ou grupo e só se justifica se usados em direção a um bem comum. Na explicação de Finnis:

Em qualquer esquema para pessoas ou grupos se apropriarem, a administração e a distribuição de coisas, embora não contrárias à natureza, será igualmente não natural, e assim tem validade moral ou legal somente em virtude de princípios e normas morais ou legais que, como todas as normas morais ou legais autenticas, são para o bem comum (FINNIS, 1998, p. 190). ${ }^{8}$

Além disso, mesmo que o proprietário confira produtividade a sua propriedade, a partir de determinando momento ele passará a ter deveres morais de medidas redistributivas em relação a quem se encontra em uma posição pior do que a sua. Para São Tomás, inicialmente há um estoque comum dos recursos naturais, e a propriedade privada é originada pela apropriação e confere o uso

\footnotetext{
${ }^{7}$ Tradução nossa. No original: "the ultimate use of resources in consumption must remain fundamentally common (unappropriated). Any appropriation of resources to particular owners is always subject to this reservation."

${ }^{8}$ Tradução nossa. No original: "any scheme for appropriating to particular persons or groups the management and distribution of things, though not contrary to nature, will equally be not natural, and so has moral or legal validity only by virtue of moral or legal principles and norms which, like all authentic moral or legal norms, are for common good."
} 
primário da propriedade. Se a parte que alguém se apropria for além de certo ponto, o excesso deve de apropriação deve retornar ao estoque comum. Ou seja, a partir de certo ponto há deveres positivos com os outros.

A propriedade privada é necessária para o indivíduo buscar realizar seus planos de vida. Inegavelmente uma maior quantidade de recursos permite melhores condições, até certo nível, de obter a realização dos bens humanos básicos. Depois de certo nível deixa de atender ao bem comum. Mas como que é possível equilibrar a propriedade privada e a orientação para o bem comum? A resposta tomista é: estabelecendo limites morais para a propriedade privada. Para isso, conforme IIII q. 32 .a.6, da Suma Teológica, ele faz uma classificação entre bens que são: a) recursos absolutamente necessários, necessários para a subsistência; b) recursos relativamente necessários, necessários para satisfazer suas responsabilidades e vocações, e de seus relativos (parentes); c) supérfluos, que sobram após a realização das duas categoria anteriores. Desta distinção seguem-se duas proposições:

I) tudo que alguém tem é considerado como comum (ou em comum) no sentido que é moralmente disponível, como questão de direito e justiça, para qualquer um que precise dele para sobreviver; 2) a propriedade superflua de alguém é considerada comum, no sentido de que a pessoa tem o dever de justiça de dispor deles em benefício dos pobres (FINNIS, 1998, p. 191). ${ }^{9}$

Pela primeira proposição, quem se encontra em uma situação de extrema necessidade, tendo a sua própria vida, ou de seus dependentes, ameaçada pode se apropriar da propriedade de outrem para satisfazer suas necessidades básicas. Nesse tipo de caso que envolve urgência, é uma exigência de justiça, não apenas caridade, dispor de recursos relativamente necessários (mesmo que não sejam supérfluos) para outros que estejam em uma situação extrema. Se dois sujeitos só possuem o absolutamente necessário, não haveria propriamente dever redistributivo, mas outras virtudes poderiam assumir o protagonismo e influenciar o julgamento prático dos sujeitos.

Pela segunda proposição, quem já supriu as necessidades relativas próprias, e das pessoas próximas e ainda possui propriedade supérflua, tem o dever de promover medidas redistributivas para com os outros. Porém, o limite de quando começa a propriedade supérflua não é claro. Tal redistribuição pode ser feita de várias formas, como geração de empregos, investimento em pesquisa, ou seja, qualquer via que se reverta para o bem comum. No mundo real, em que nem todo mundo possui recursos necessários para garantir um mínimo existencial, quem tem recursos

\footnotetext{
${ }^{9}$ Tradução nossa. No original: “ i) everything one has is held as common (or in common) in the sense that is morally available, as a matter of right and justice, to anyone who needs it to survive; 2) one's superflua are all held as common, in the sense that one has a duty of justice to dispose of them for the benefit of the poor".
} 
superabundantes está, de fato, para São Tomás, roubando. Reter o supérfluo é uma forma de violencia (AQUINO, 2005, p. 672-674).

Neste contexto, medidas de tributação que visam custear políticas redistributivas estariam fundamentadas. Se os possuidores não cumprem esse dever, a autoridade pública pode tributar ${ }^{10}$, ou até expropriar. Nas palavras de Finnis, o Estado.

ao estabelecer um esquema de tributação redistributiva etc., o Estado não precisa estar fazendo mais do que cristalizar e impor deveres que o proprietário já tinha. A coerção, portanto, só entra em jogo no caso de recalcitrância, que é delituosa não apenas de acordo com a lei, mas também de acordo com a justiça. A justiça distributiva é aqui, como na maioria dos contextos, uma relação entre cidadãos, ou grupos de associações dentro da comunidade, sendo de responsabilidades desses cidadãos e grupos. O papel das autoridades governantes e da lei, na determinação, para comunidades políticas particulares, dos requisitos particulares de justiça distributiva, é um papel decisivo, mas subsidiário (FINNIS, 2007, p. $185)$.

A coerção surgiria em caso de insistência de cumprir a exigência de justiça. Em Tomás, a justiça distributiva é uma relação entre cidadãos. O Estado atual de forma subsidiaria nesta questão. Desta argumentação pode-se concluir que para a vertente clássica são possíveis medidas redistributivas por meio da atuação do Estado. Mas disso não se segue a legitimidade de qualquer regime tributário - que pode sim ter excessos e atrofiar o bem comum. Uma exposição mais ampla do pensamento de Finnis permitiria pontuar melhor os critérios formais propostos sobre este tópico. Entretanto, para a argumentação proposta neste artigo, o exposto é suficiente.

\section{A CLASSIFICAÇÃO RECENTE E A JUSTIÇA DISTRIBUTIVA PARA NOZICK}

No século XVI o neotomista Cardeal Thomas de Vio Cajetano e Domingos Soto reestruturaram a classificação da justiça - que reaparece em outros teóricos tomistas, como Johannes Messner, Heinrich Rommen, Josef Pieper. Cajetano, em seus comentários a Suma Teológica de São Tomás, identificou três justiças distintas. Ele escreveu:

\footnotetext{
${ }^{10}$ A posição apresentada por Finnis é que tais medidas são possíveis, não que devem ser feitas. A doutrina tomista diz como o direito positivo pode ser, não como ele deve ser.
} 
Existem três espécies de justiça, assim como existem três tipos de relação em qualquer totalidade: as relações das partes entre si, as relações do todo com as partes e as relações das partes com o todo. Da mesma forma, existem três justiças: a legal, a distributiva e a comutativa. Pois que a justiça legal orienta as partes em relação ao todo, a distributiva orienta o todo em relação às partes, e a comutativa orienta as partes uma em relação às outras (apud FINNIS, 2007, p. 182-3).

A primeira é a comutativa, que é relativa a trocas. Ter como elemento intersubjetivo dois ou mais indivíduos, que relacionando-se entre si conferem um ao outro (s) o que é devido em virtude de um contrato ou dano causado, sendo observada uma igualdade absoluta.

A segunda é a distributiva, que ocorre entre uma parte e o todo. A intersubjetividade é entre um indivíduo e o todo. Justiça distributiva passa a ser considera uma virtude da autoridade. O devido é participação no estoque comum de bens da comunidade, ou do Estado, que confere aos seus membros uma parcela seguindo uma igualdade relativa, ou geométrica em termos aristotélicos. Aplicável para repartir cargos públicos, compensar injustiças sociais, fundamentar reforma agrária etc.

A terceira e última, a legal também tem como partes da relação intersubjetiva: indivíduos e todo, mas agora com a relação de ônus invertida em relação a justiça distributiva. A exigibilidade do dever reside no todo, personificado no Estado, que impõe prestações em relação aos indivíduos, comumente feito através de normas jurídicas que criam um conjunto de obrigações e proibições, sempre seguindo uma igualdade proporcional na medida em que obrigações diferentes são impostas para sujeitos diferentes. Tais prestações devem ser orientadas para um tipo de bem comum, conceito que assume contornos diferentes conforme o marco teórico, o que por vezes recebe perigosos esvaziamentos semânticos, como ocorre com o positivismo jurídico.

Trata-se de outra classificação de justiça quando comparada com a clássica. Em vez de um modelo em que há uma justiça geral com duas espécies, passa a existir três tipos autônomos de justiça. Essa nova forma de perceber a justiça tem consequências enumeradas por Ryan T. Anderson e Finnis (ANDERSON, 2014, p. 282-283; FINNIS, 2007, p. 183).

1. Essa classificação não honra a compreensão aristotélica e tomista de justiça, e é incapaz de gerar uma sólida teoria da justiça;

2. tal classificação ignora toda a discussão em relação ao bem comum;

3. todas as três justiças estão no mesmo nível (sendo que na vertente clássica a justiça legal era o fundamento das outras duas formas de justiça particular); Para São Tomás, a justiça 
legal é a base de todas obrigações, distributivas ou comutativas. Para a visão recente, a justiça legal é o dever de obediência do indivíduo ao Estado;

4. justiça legal é redefinida e reduzida como meramente positiva, regulando a relação entre indivíduo e todo, sugerindo também que o Estado pode ser equiparado com uma noção de bem comum - noção que foi desvirtuada pelo positivismo jurídico que enfatizou a justiça legal como mero dever de obedecer a lei positiva;

5. justiça redistributiva é questão unicamente do Estado, retirando dos indivíduos os deveres redistributivos. Para São Tomás, qualquer proprietário encarregado do estoque comum, considerando que os bens devem ser explorados para o bem comum, terá deveres de justiça distributiva. Na visão recente, apenas o Estado possui este tipo de dever. A nova visão é a base do argumento de Nozick contra a tributação, que acusa a natureza ilegtima da intervenção do Estado como agente de justiça redistributiva;

6. Para a visão clássica a justiça comutativa existe entre indivíduos e também entre Estado e indivíduo (por exemplo a atribuição proporcional de uma sanção). Na visão mais recente a justiça comutativa existe apenas entre indivíduos.

Anderson ainda entende que teóricos do século XX, como Hayek e Nozick, não compreenderam corretamente os fundamentos da justiça distributiva (ANDERSON, 2014, p. 3934). Na seção seguinte veremos como que Nozick assenta sua teoria da justiça unicamente em uma concepção de justiça comutativa, contrariando a teoria da justiça aristotélico-tomista.

\subsection{FUNDAMENTOS MORAIS DO LIBERTARIANISMO}

Robert Nozick (1938-2002) é partidário de um modelo neoliberal com fundamentação em uma teoria moral. Seguindo os comentários de Álvaro de Vita, acima de razões pragmáticas há uma moralidade que justifica medidas de desregulamentação do mercado, redução de subsídios públicos e reformas legislativas para a diminuição do Estado. Por trás de lemas como "Mais mercado, menos Estado" há razões para a ampliação da liberdade individual. Mas nisso não se nega que intervenções econômicas podem produzir um crescimento econômico mais eficiente - busca-se um bem-estar econômico também, mas isso é secundário face a valorização da liberdade. E isso é consequência das premissas adotadas que envolvem argumentos de justiça. Logo, se o fundamento de justiça nozickiano for afetado, sua teoria perde espaço.

A tese central de Nozick consiste em afirmar que políticas redistributivas são moralmente erradas. O Estado de bem-estar social afronta a liberdade. Na defesa destas proposições há uma justifica moral - ainda que questionável. Seu discurso é desenvolvido realizando contrapontos com 
teorias igualitárias, em especial em relação ao modelo de John Rawls que propõe um estado final a ser realizado. Nozick escreveu o livro "Anarquia, Estado e Utopia", onde apresenta seu libertarianismo. Traz uma concepção de Justiça fundada em Direitos individuais e realiza uma critica as teorias que não conferirem liberdade suficiente. Nozick argumenta que Rawls, assim como o utilitarismo, não leva a sério a distinção entre as pessoas. Face uma igualdade forte, Nozick defende uma concepção forte de liberdade - que aparece como valor fundamental que deve ser assegurado através de "restrições de ação". O propósito da teoria libertária é garantir espaço para a autonomia individual, não um estado final a ser realizado envolvendo alocação de recursos. Podemos fazer qualquer coisa desde que não violemos direitos dos outros, pois isso seria moralmente errado (VITA, 2007, p. 34-6).

Rawls e Nozick possuem uma diferença central quanto a visão sobre o papel do Estado. Para o primeiro é preciso um arranjo institucional efetivo no campo da justiça distributiva. Para o segundo, o Estado deve ser mínimo, atuando apenas em uma dimensão negativa, garantindo que ninguém vai violar a propriedade da pessoa, sua vida, sua liberdade. Para Nozick os Direitos definem o que não podemos fazer, possuindo apenas uma dimensão negativa. As pessoas são donas de si mesmas, por isso não há justificativa que me autorize sacrificar os interesses de um em benefício de todos (VITA, 2007, p. 37). Assim, para Nozick, toda contribuição forçada para o bem estar social viola direitos individuais, pois o Estado trataria as pessoas como meio a atingir determinado fim. Para fundamentar isso, ele realiza uma interpretação forte da segunda formulação do imperativo categórico kantiano que enuncia: "tratar a humanidade em nós mesmos ou em outro, não como meio mas como fim em si." Como atributos da humanidade da pessoa estão inseridos todas as circunstâncias de sua vida, talentos e propriedades. ${ }^{11}$ Em suas palavras:

Uma restrição indireta específica relativa a uma voltada para os outros exprime o fato de que eles não podem ser usados das formas específicas que a restrição indireta exclui. As restrições indiretas expressam, das maneiras especificadas por elas, a inviolabilidade dos outros. Essas formas de inviolabilidade são expressas pela seguinte injunção: "Não use as pessoas de tal ou tal maneira". Por outro lado, a visão baseada na situação final expressaria o fato de que as pessoas são fins e não simplesmente meios (se se chegar a expressar essa visão) por meio de uma injunção diferente minimize o uso, dessa ou daquela maneira, da pessoas como meios. A obediência a esse preceito pode, por si mesma, implicar o uso de alguém como meio de uma das maneiras especificadas. Se fosse essa a concepção de Kant, ele teria enunciado assim a segunda fórmula do imperativo categórico: "age

${ }^{11}$ Tal assunção, para Vita, não é fundamentada por Nozick. Outros autores, como Rawls, já discutem o que caracteriza essa identidade pessoal. 
a fim de minimizar o uso da humanidade simplesmente como meio", e não como, na verdade, o fez "age de forma tal a sempre tratar a humanidade, seja na tua própria pessoa ou na dos outros, nunca simplesmente como meio, mas sempre, e ao mesmo tempo, como um fim (NOZICK, 2011, p. 39-40). ${ }^{12}$

Somente são possíveis a imposição de deveres negativos ao indivíduo. Um conjunto de proibições que o impeçam de causar dano a outrem. Deveres positivos, que obriguem um fazer em benefício de outrem seria uma violação a liberdade. Seguindo este caminho, privar uma pessoa de sua renda para redistribuir seria como tratá-la como meio, isto é, seria violar a humanidade da pessoa. Assim, Nozick considera medidas redistributivas como violação ao preceito kantiano. Redistribuição seria usar o rico como instrumento para o menos afortunado. Nenhum objetivo social poderia justificar tamanha constrição moral. Sobre este tema em particular ele desenvolve as seguintes considerações:

A tributação da renda gerada pelo trabalho equivale ao trabalho forçado. Para algumas pessoas, a verdade contida nessa afirmação é evidente: apropriar-se do pagamento de $n$ horas de trabalho é como apropriar-se de $n$ horas da pessoa; é como obrigar a pessoa a trabalhar $n$ horas em prol dos objetivos de outrem. Outras consideram a afirmação absurda. Mas mesmo estas, se forem contra o trabalho forçado, se oporiam a que os hippies desempregados fossem obrigados a trabalhar em prol dos necessitados. E também se oporiam a que cada um trabalhasse cinco horas extras por semana em prol dos necessitados. Mas um sistema que se apropria do salário de cinco horas de trabalho por meio de impostos não lhes parece igual àquele que obriga alguém a trabalhar cinco horas, já que ele oferece à pessoa que é objeto da imposição um leque mais amplo de atividades opcionais do que a tributação em espécie do trabalho específico mencionado (NOZICK, 2011, p.217).

Em seu modelo, o Estado deve ser neutro em relação aos fins perseguidos por seus cidadãos. Por isso deve ser um Estado centrado em evitar que os cidadãos causem danos uns aos outros. Vita explica que:

\footnotetext{
${ }^{12}$ Essa interpretação da segunda formulação do imperativo categórico pode ser contestada a partir de um viés kantiano. De fato, Kant enuncia e defende essa máxima formal, no entanto, tal princípio é uma exigência da razão prática dentre outras. A interpretação de Nozick restringe a filosofia moral kantiana desrespeita o pensamento de Kant.
} 
Um Estado justo e neutro em relação aos fins perseguidos por seus cidadãos nada mais é do que um Estado que garante o respeito às constrições morais à conduta individual e, acima de tudo, que as respeita no que se refere à sua própria ação. Um Estado que força uma pessoa (mais privilegiada) a contribuir para o bem-estar de outra (mais desafortunada) admite, segundo Nozick, que a primeira seja utilizada como instrumento para os fins da segunda, e, portanto, é um Estado que não é neutro entre seus cidadãos (VITA, 2007, p. 39).

Um Estado justo limita-se dar os limites de interdições ou constrições deontológicas, quem não cumpri-las deve ser coagido. Isso permite expor um desdobramento forte e polêmico do pensamento de Nozick. O dever do indivíduo é apenas em relação a sua conduta no mundo. Deve evitar causar dano a outrem, mas não implica que deva evitar que ocorra injustiças no mundo (VITA, 2007, p. 45).

Nozick sustenta um modelo de Estado mínimo com três funções: defesa nacional, poder de polícia e sistema judicial. Para custear tais instituições é inegável que alguma taxação há de existir. Porém, não é problema do Estado garantir que os indivíduos tenham condições de cumprir suas obrigações tributárias. ${ }^{13}$ Já outras teorias da justiça se preocupam em criar condições para que os indivíduos tenham condições de cumprir suas obrigações para com o Estado - assim como a justiça clássica faz. Nenhuma moralidade pública plausível pode ser fundada em um modelo que não trás considerações pelos outros além de razões morais relativas ao agente.

Para justificar tal posição, Nozick nega que tenhamos alguma responsabilidade negativa por omissão em relação às circunstâncias de vida dos outros. Só não podemos ser responsáveis diretamente por danos causados a terceiros. Mas não precisamos fazer nada para evitar eventos danosos. ${ }^{14}$ Deveres positivos são vistos como moralmente opcionais (VITA, 2007, p. 50).

\footnotetext{
${ }^{13}$ Álvaro de Vita realiza uma crítica ao sustentar que a capacidade de cada um cumprir seus próprios deveres depende que os outros também o façam. Seria preciso criar um Estado em que todos tem meio de desempenhar seus deveres. Em termos de cooperação, tal crítica é muito forte, pois não teríamos os melhores resultados possíveis, dentro de um modelo teórico da teoria dos jogos. Cada um deve apenas se limitar a cumprir suas obrigações e é problema do outro a capacidade dele cumprir seus deveres. Tal concepção libertariana necessitaria que o Estado capacitasse todos os seus membros a respeitar os deveres atribuídos. Outras vertentes do libertarianismo, como o real-libertarianismo, preocupa-se mais com o acesso aos meios para capacitar as pessoas. Logo devemos necessariamente ter alguma consideração pelos outros.

${ }^{14}$ Imagine que um sujeito A vai causar dano a B. C pode evitar se causar dano menor a D. Por exemplo, C pode impedir que A mate B se pegar o celular de D, sem permissão, para chamar a polícia. Neste exemplo existem dois cenários possíveis. Um de interferência e outro não. A não-interferência é superior para Nozick. Quem faltou com o dever foi $\mathrm{A}$, mas isso não torna $\mathrm{C}$ co-responsável. Além do mais, se $\mathrm{C}$ interferisse estaria agindo de forma moralmente errada em relação a $\mathrm{D}$, pois tem o dever de não causar dano. A objeção de Vita é que a melhor proteção da liberdade de todos é protegida quando $\mathrm{C}$ intervém.
} 
Desdobrar questões sobre a aquisição da propriedade esclarecerá este tópico, além de permitir um contraponto mais claro com a posição tomista.

\subsection{A TEORIA DE NOZICK DA APROPRIAÇÃO DA PROPRIEDADE}

Nozick não se propõe a avaliar um Estado das coisas - como o utilitarismo e Rawls o fazem. Apenas a justiça na aquisição da propriedade. Se a aquisição foi justa qualquer resultado será justo - não importando se alguém tem posses supérfluas e outros nem os recursos absolutamente necessários. Independente da desigualdade existente, se a distribuição foi atingida seguindo seus princípios, ela é justa.

Três princípios resumem o pensamento de Nozick sobre a propriedade: 1 Aquisição original da propriedade; 2 Princípio de livre transferência; e 3 Princípio de retificação de posses obtidas por meios que violem os princípios anteriores. Se a titularidade da propriedade observa os dois primeiros princípios as pessoas tem um direito moral sobre suas posses (VITA, 2007, p. 56).

O primeiro princípio segue uma linha lockeana para fundamentar o direito de propriedade. Para isso, faz um apelo intuitivo defendendo que: $i$ Cada um é proprietário de si mesmo (e isso inclui talentos e capacidades); e ii se sou proprietário de mim mesmo, o que adquiri através de minhas capacidades é igualmente meu. Diante disso, se é aceito um Direito moral sobre si mesmo, a tributação é impossível. Isso remonta à tese central de Nozick de que políticas redistributivas são injustas. A existência de pessoas em estado de privação não justifica o Estado a intervir na propriedade dos mais abastados. O sistema tributário é tão injusto quanto tirar o órgão de uma pessoa (SANDEL, 2016, p. 86-7). Se uma uma pessoa tem a liberdade violada, perdendo uma propriedade, o que impede o Estado de violar meu corpo e retirar um órgão? Questionamentos desta natureza são formulados pelo libertarianismo.

Pelo segundo princípio, o de livre transferência, trocas voluntárias que geram desigualdade de renda são válidas. Desde que não haja coercitividade, um resultado desigual é justo (VITA, 2007, p. 60). ${ }^{15}$

Por outro lado, se deixarmos o Estado de lado e perguntarmos para um cidadão se ele tem deveres de justiça distributiva (pergunta inconcebível pós-Cajetano), o raciocínio de Nozick se a aquisição é justa, a manutenção é justa, tem pouco a dizer.

\footnotetext{
${ }^{15}$ Nozick propõe também um terceiro princípio. Se os dois primeiros princípios forem violados, é preciso retificar as injustiças. Princípio de retificação possui a seguinte formulação: "organize-se a sociedade de forma a elevar ao máximo a posição de qualquer grupo que nela acabe por se encontrar na situação mais desvantajosa" (VITA, 2007, p. 66). Neste contexto, até um defensor forte da liberdade, reconhece a necessidade de politícas redistributivas para a correção de injustiças decorrentes da ausência dos dois princípios propostos.
} 


\section{CONCLUSÃO}

São Tomás propõe uma maneira diferente de refletir a justiça da que está presente no debate contemporâneo em torno da obra de Rawls. A divergência essencial que surge a partir da contraposição entre os modelos discutidos, antes e depois da classificação sobre a justiça de Cajetano, é que para os clássicos a justiça integra uma teoria moral e existem obrigações morais intersubjetivas que existem independnete do Estado. Já para os autores modernos e contemporâneos, de uma forma geral, tais deveres não aparecem e o debate confere destaque ao que o Estado deve ou não fazer. Rawls, com seu liberalismo igualitário, assim como o libertarianismo de Nozick, bem como outros autores presentes no debate, pressupõe a mesma inexistência de deveres redistributivos entre indivíduos, vez que tal responsabilidade é restrita, quando aplicáveis, às instituições básicas da sociedade.

As consequencias das diferentes perpectivas ficam evidentes no caso dos fundamentos da taxação por parte do Estado. Para o modelo clássico, a autoridade estatal teria toda a legitimidade moral para arrecadar recursos (obviamente não de forma abusiva) para custear programas sociais. Autores do New Natural Law defendem esta posição estatista. Para o modelo pós-Cajetano, a taxação é vista como injustificável por algumas teorias (notadamente os libertários) e possível de justificativa a partir de argumentos que recorrem a uma noção de imparcialidade a partir de um estado de coisas (como os modelos igualitários). Em síntese, para os clássicos a justiça reside essencialmente na conduta de uma pessoa, para o modelo mais recente é vista em um estado de coisas.

Esses desdobramentos, que decorrem das diferentes premissas adotadas, resultam em percepções distintas da realidade objeto de reflexões filosóficas. No debate contemporâneo, em especial em Nozick, há uma visão restritiva acerca da moral e da conduta humana. Por outro lado, os clássicos situam a justiça como parte de uma teoria moral que tem pretensões de objetividade, que se observada, garante a justiça no agir de um sujeito. Para os clássicos a justiça está principalmente na conduta das pessoas e apenas secundariamente em um estado de coisas. Os contemporâneos postulam questões morais de forma diferente e nisso a discussão da justiça andetra outro âmbito - variável conforme o marco teórico, sendo para Rawls um estado de coisas assegurado por instituições, e para Nozick a forma de aquisição original. De todo modo às teorias contemporâneas de justiça não possuem uma conexão com a uma teoria moral - exceto pelo utilitarismo, mas uma moral utilitária apresenta fragilidades amplamente criticadas na filosofia.

Essa pesquisa também comparou os fundamentos da aquisição do direito de propriedade em dois autores diferentes. Em São Tomás a propriedade é originariamente comum e a apropriação privada só se justiça em função do bem comum. Ou seja, quem toma algo para si o que antes era de 
todos, deve reverter algum benefício para todos, tendo um fim social ou simplesmente atender ao bem comum. Para Nozick, se a propriedade foi adquirida atendendo certos requisitos, o proprietário não possui limitação no exercício do direito de propriedade, e toda interferência em seu domínio seria injustificada moralmente. Sem emitir juízo de valor sobre qual teoria é a correta, constatou que a que a visão de um filósofo sobre a propriedade afeta sua teoria da justiça.

A inserção da justiça no contexto de uma teoria moral também permite tratar outras questões além de políticas redistributivas. Como exemplos evidentes pode-se incluir o debate sobre a justificativa moral de haver uma legislação paternalista, que visa proteger o sujeito dele próprio, como casos de consumo de drogas ou eutanásia; a existência de uma legislação ambiental a partir de uma fundamentação moral, e não simplesmente em uma análise econômica de sustentabilidade; bem como revisitar os fundamentos da coerção exercida pelo Direito.

Além de criticar o discurso libertário e oferecer outra perspectiva para visualizar as questões de justiça, outra aplicação das reflexões desenvolvidas nesta pesquisa, seria criticar modelos teóricos que esvaziam o conceito de justiça. O positivismo jurídico, por exemplo, defende uma identificação entre justiça e legalidade, de forma que aquilo que tem previsão legal (ainda que questionável a partir de uma perspectiva ética) seria justo. Entretanto, para o pensamento tomista, o Direito Positivo só encontra legitimidade a partir de uma teoria que considere questões de justiça e morais fundamentadas na razão prática.

O conceito de justiça é central em qualquer sistema de Filosofia do Direito. Apenas do conhecimento da concepção de justiça de um modelo já é possível ter uma noção do papel do Direito e do Estado. Esta pesquisa, mesmo não tendo como foco central discutir o New Natural Law, apresentou aspectos essenciais desta linha de pensamento que resgata a tradição tomista.

\title{
THE GROUNDING OF DISTRIBUTIVE JUSTICE IN ST. THOMAS AQUINAS'S : A CRITICAL TO ROBERT NOZICK'S LIBERTARIANISM
}

\begin{abstract}
Two classifications of justice are presented and compared in this paper - which emphasizes the consequences of existing differences. For this, on the one hand it presents the classical AristotelianThomist classification, which will be discussed from the New Natural Law; and on the other hand, the classification of justice that emerged from the sixteenth century with Cardinal Cajetan and the most extreme consequences of his model expressed in the Robert Nozick's Libertarianism - that was elected as theoretical framework because he have the greatest contrast with Thomistic thought. The importance of understanding the differences between the classifications of justice lies in the
\end{abstract}


fact that they have consequences in the philosophical debate, especially in moral questions and foundations for redistributive justice affected by State institutions. It is bibliographical research that uses a comparative method, identifying in both classifications the essential concepts - the types of justice and the foundation of property right - and presents a systematization of differences. As a result of the analysis made, it identifies as main divergence between the models the treatment for positive moral duties. This study presents essential theoretical elements of the New Natural Law and also offer a solid counterpoint to Nozick's thought.

KEYWORDS: John Finnis; Natural Law; Property; Classification of Justice; Moral Duties.

\section{REFERÊNCIAS}

ANDERSON, Ryan T. Neither Liberal Nor Libertarian: A Natural Law Approach to Social Justice and Economic Rights. Tese (Doutorado em Ciência Política) Universoty of Notre Dame, NOTRE DAME, p. 434. 2014.

AQUINO, Santo Tomás de. Suma Teológica. Vol. VI. São Paulo: Loyola, 2005.

Da Justiça. Tradução de Tiago Tondinelli. Campinas/SP: Vide Editorial, 2012.

ARISTÓTELES. Ética a Nicômacos. Trad. Mário da Gama Kury. 3 ed. Brasília: Universidade de Brasília, 1999.

FINNIS, John Mitchell. Lei Natural e Direitos Naturais. Trad. Leila Mendes. São Leopoldo: Unisinos, 2007.

Natural Law and Natural Rights. New York: Oxford University Press, 1980.

Aquinas: Moral, Political and Legal Theory. Oxford University Press, New York, 1998.

GARGARELLA, Roberto. As teorias da justiça depois de Rawls: um breve manual de filosofia política. Trad. Alonso Reis Freire. São Paulo: Martins Fontes, 2008. 
KELSEN, Hans. O que é Justiça? Trad. Luís Carlos Borges. São Paulo: Martins Fontes, 2001.

KYMLICKA, Will. Filosofia Política Contemporânea. Trad. Luís Carlos Borges. São Paulo: Martins Fontes, 2006.

MONTORO, André Franco. Introdução à Ciência do Direito. 27 ed. São Paulo: Revista dos Tribunais, 2008.

NOZICK, Robert. Anarquia, Estado e Utopia. Trad. Fernando Santos. São Paulo: Martins Fontes, 2011.

SANDEL, Michael J. Justiça: o que é fazer a coisa certa. Trad. Heloísa Matias e Maria Alice Máximo. 20 ed. Rio de Janeiro: Civilização Brasileira, 2016.

VITA, Álvaro de. A justiça igualitária e seus críticos. 2 ed. São Paulo: Martins Fontes, 2007.

Trabalho enviado em 28 de janeiro de 2019

Aceito em 06 de fevereiro de 2020 